\title{
Dopant-Assisted Atmospheric Pressure Photoionization Mass Spectrometry of Polyisobutylene Derivatives Initiated by Mono- and Bifunctional Initiators
}

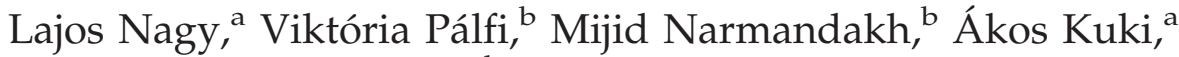 \\ Andrea Nyíri, ${ }^{a}$ Béla Iván, ${ }^{b}$ Miklós Zsuga, ${ }^{a}$ and Sándor Kéki ${ }^{a}$ \\ a Department of Applied Chemistry, University of Debrecen, Debrecen, Hungary \\ ${ }^{b}$ Institute of Materials and Environmental Chemistry, Chemical Research Center, Hungarian Academy of \\ Sciences, Budapest, Hungary
}

Nine polyisobutylene (PIB) derivatives with different end groups (chlorine, vinyl, isobutenyl, 2,2-diphenylvinyl, and carboxyl) and molecular weights (1000 to $4500 \mathrm{~g} / \mathrm{mol})$, initiated by monofunctional and aromatic bifunctional initiators were studied by atmospheric pressure photoionization mass spectrometry (APPI-MS) in both negative and positive ion modes. Consistent with previous findings, negative ion APPI-MS revealed end-group identities through the formation of PIB adducts with chloride ions formed in situ from a chlorinated solvent (e.g., $\mathrm{CCl}_{4}$ ) in the presence of a dopant (toluene). In positive ion mode, considerable fragmentation of these PIB derivatives was observed, rendering end-group determinations very difficult. The $\mathrm{M}_{n}$ values obtained by APPI(-)-MS were considerably lower than those determined by SEC for PIB derivatives with $\mathrm{M}_{n}$ higher than $2000 \mathrm{~g} / \mathrm{mol}$. PIBs containing carboxyl termini can undergo collision-induced dissociation, yielding structurally important product ions. The resulting APPI-MS/MS intensities were found to reflect the "arm-length" distribution for PIBs with bifunctional aromatic moieties. In positive ion mode, $[\mathrm{M}+\mathrm{COCl}]^{+}$ adducts were observed for PIBs with an aromatic initiator moiety. The origin of the $\mathrm{COCl}^{+}$ species is also discussed. (J Am Soc Mass Spectrom 2009, 20, 2342-2351) @ 2009 Published by Elsevier Inc. on behalf of American Society for Mass Spectrometry

$\mathrm{L}$ ow molecular weight polyisobutylenes are of great scientific and practical interest. Due to the high hydrophobicity and chemical stability of polyisobutylenes, they are used as additives in sealants, lubricants, coatings, and insulators and, due to their nontoxic nature, they are also used in food contact applications [1]. The hydrophobicity and biocompatibility of polyisobutylenes with certain tissues leads to their frequent use as macroinitiators in the synthesis of amphiphilic block copolymers and/or as a hydrophobic building block for networks/co-networks [2-4] and amphiphilic micelles/vesicles [5-8]. Moreover, the molecular weights and the end groups of these low molecular weight polyisobutylenes play significant roles in determining their properties and their further applications. For instance, for them to be used as a macroinitiator, i.e., for the preparation of amphiphilic block copolymers or networks, the identities of the end groups and the average functionality $\left(\mathrm{F}_{n}\right)$ must be known to obtain well-controlled structures and architectures. Determining the end groups and molecular

Address reprint requests to Dr. S. Kéki, Department of Applied Chemistry, University of Debrecen, H-4010 Debrecen, Egyetem ter 1, H-4010 Debrecen, Hungary. E-mail: keki@tigris.unideb.hu weights of low molecular weight polyisobutylenes is therefore essential to achieve these goals, where this can be done by means of several traditional methods, including nuclear magnetic resonance spectroscopy (NMR) and/or infrared spectroscopy (IR) for endgroup and number-average functionality determinations, and size exclusion chromatography (SEC) for molecular weight measurements. However, the above methods either provide only average values for these essential parameters (e.g., NMR, IR) or yield molecular weights relative to the calibrant (e.g., SEC).

As opposed to the these traditional methods, mass spectrometry employing soft ionization techniques, such as matrix-assisted laser desorption/ionization (MALDI) [9, 10] or electrospray ionization (ESI) [11], are able to determine the number-average molecular weight and functionality, and may also be used to record individual polymer chains, which allows the identity of the end groups and the repeat units to be easily assessed.

The main drawback of MALDI and ESI is that the polymers to be analyzed must have effective sites for ionization, such as is the case of polar polymers, e.g., polyethylene glycol (PEG) and polypropylene glycol (PPG), where ionization occurs most generally through 
the formation of adducts with metal ions (e.g., $\mathrm{Na}^{+}, \mathrm{K}^{+}$, $\mathrm{Ag}^{+}$, etc.) or via protonation and/or deprotonation processes. However, mass spectrometric analysis of highly nonpolar isobutylene with a fully saturated structure by MALDI and/or ESI fails due to the lack of appropriate ionization sites. It has also been shown that the introduction of aromatic moieties (e.g., using aromatic initiators for the isobutylene polymerization) and/or polar or readily ionizable groups into the polyisobutylene facilitates the ionization under MALDI and ESI conditions [12-17]. It is therefore evident that nonpolar polymers like polyisobutylenes are not amenable to MS analysis due to the lack of effective site for ionization.

Fortunately, over the past years, a new ionization method referred to as atmospheric pressure photoionization (APPI) has been introduced by Bruins [18] and Syage [19] to broaden the range of analytes, especially towards compounds of low polarity. This method has been successfully applied to the analysis of various classes of nonpolar compounds, such as polyaromatic hydrocarbons [20-22], lipids [23, 24], and steroids [25-28]. Very recently, we have shown that the negative ion mode of APPI-MS is also capable of the analysis of low molecular weight polyisobutylene [29] and polyethylene derivatives [30] by means of the formation of adducts of these polymers with chloride ions formed "in situ" from chlorinated solvents, e.g., $\mathrm{CCl}_{4}, \mathrm{CH}_{2} \mathrm{Cl}_{2}$, in the presence of toluene dopant. From these investigations, we have concluded that the chloride ion can attach to the partially positively charged $\mathrm{H}$-atoms of the hydrocarbon chain and to those of the end groups. However, there has been no direct investigation into the applicability of APPI-MS for end-group determination of polyisobutylene derivatives with a broader range of end groups, as well to obtain the molecular weights of the polyisobutylenes accessible by APPI-MS.

As an extension of our work on the APPI-MS of polyisobutylenes, we report herein a detailed investigation on nine polyisobutylene derivatives with different molecular weights and various end groups, including vinyl, isobutenyl, chlorine, 2,2-diphenylvinyl, methoxy, and carboxyl, attached terminally to the chain initiated by aromatic bifunctional or nonaromatic monofunctional initiators. These polyisobutylene derivatives allowed us to study the effects of the end groups and molecular weights on the resulting APPI-MS spectra. In addition, it is shown that the chlorinated adducts of polyisobutylenes with carboxyl termini can undergo collision-induced dissociation to yield structurally important product ions.

\section{Experimental}

\section{Chemicals}

The polyisobutylene (PIB) derivatives investigated in this study are compiled in Table 1 .
All of the PIB derivatives were prepared by quasiliving/living cationic polymerization according to the method described in references [31-35]. The other reagents were received from Sigma-Aldrich (Seelze, Germany). Each solvent used was of HPLC grade. The polymers were characterized by ${ }^{1} \mathrm{H} \mathrm{NMR},{ }^{13} \mathrm{C} \mathrm{NMR}$, and size exclusion chromatography (SEC).

\section{Instrumentation}

Atmospheric pressure photoionization ionization quadrupole timeof-flight mass spectrometry (APPI-Qq-TOF MS). APPI-QqTOF MS measurements were performed in positive and negative ion modes with a MicroTOF-Q type Qq-TOF MS instrument (Bruker Daltonik, Bremen, Germany) equipped with an atmospheric pressure photoionization (APPI) source (PhotoMate, $\mathrm{Kr}$ discharge lamp, VUV photons of 10.0, and $10.6 \mathrm{eV}$ in intensity ratio of 4:1, respectively) from Syagen Ltd. (Syagen Technology, Inc., Tustin, CA). The PIB samples were dissolved in toluene (dopant) at a concentration of $1 \mathrm{mg} / \mathrm{mL}$. The PIB solutions were delivered directly into the APPI source with a syringe pump (Cole-Parmer Ins. Co., Vernon Hills, IL, USA) at a flow rate of $25 \mu \mathrm{L} / \mathrm{min}$ together with a carrier flow of $\mathrm{CCl}_{4}$ at a flow rate of 200 $\mu \mathrm{L} / \mathrm{min}$ by means of a T-piece. The heater of the APPI source was kept at $400{ }^{\circ} \mathrm{C}$. The end-plate offset and capillary voltage were set to $-500 \mathrm{~V}$ and $2500 \mathrm{~V}$, respectively.

For MS/MS experiments, nitrogen gas was used as the collision gas and the collision energies were varied in the range $5-140 \mathrm{eV}$ (in the laboratory frame). The pressure in the collision cell was determined to be $\sim 8 \times$ $10^{-3}$ mbar. The precursor ions for MS/MS were selected with an isolation width of 5 . All of the spectra were recorded by a digitizer at a sampling rate of 2 GHz. The spectra were calibrated externally with the APCI/APPI calibrant mixture from Bruker in the $m / z$ range $600-1600$. The accuracy of the $m / z$ determination was less than 0.01 in most cases. The mass spectra recorded were evaluated by the DataAnalysis 3.1 software from Bruker.

Matrix-assisted laser desorption/ionization time-of-flight mass spectrometry (MALDI-TOF MS). MALDI-TOF MS measurements were performed with a Bruker BIFLEX III mass spectrometer equipped with a time-of-flight (TOF) mass analyzer. In all cases, a $19 \mathrm{kV}$ acceleration voltage was used with pulsed ion extraction (PIE). The ions were detected in the reflectron mode $(20 \mathrm{kV})$. A nitrogen laser ( $337 \mathrm{~nm}, 3 \mathrm{~ns}$ pulse width) operating at 4 $\mathrm{Hz}$ was used to produce laser desorption and 100-500 shots were summed. The spectra were externally calibrated with a polystyrene standard $\left(M_{n}, 2200 \mathrm{~g} / \mathrm{mol}\right.$, $\left.M_{\mathrm{w}} / M_{\mathrm{n}}, 1.01\right)$ by linear calibration. Samples were prepared with a dithranol matrix $(20 \mathrm{mg} / \mathrm{mL})$, polymer solutions of $3 \mathrm{mg} / \mathrm{mL}$ in tetrahydrofuran and silver trifluoroacetate in tetrahydrofuran $(1 \mathrm{mg} / \mathrm{mL})$ as the cationization agent. The above solutions were mixed in 
Table 1. Structures of the investigated polyisobutylene (PIB) derivatives

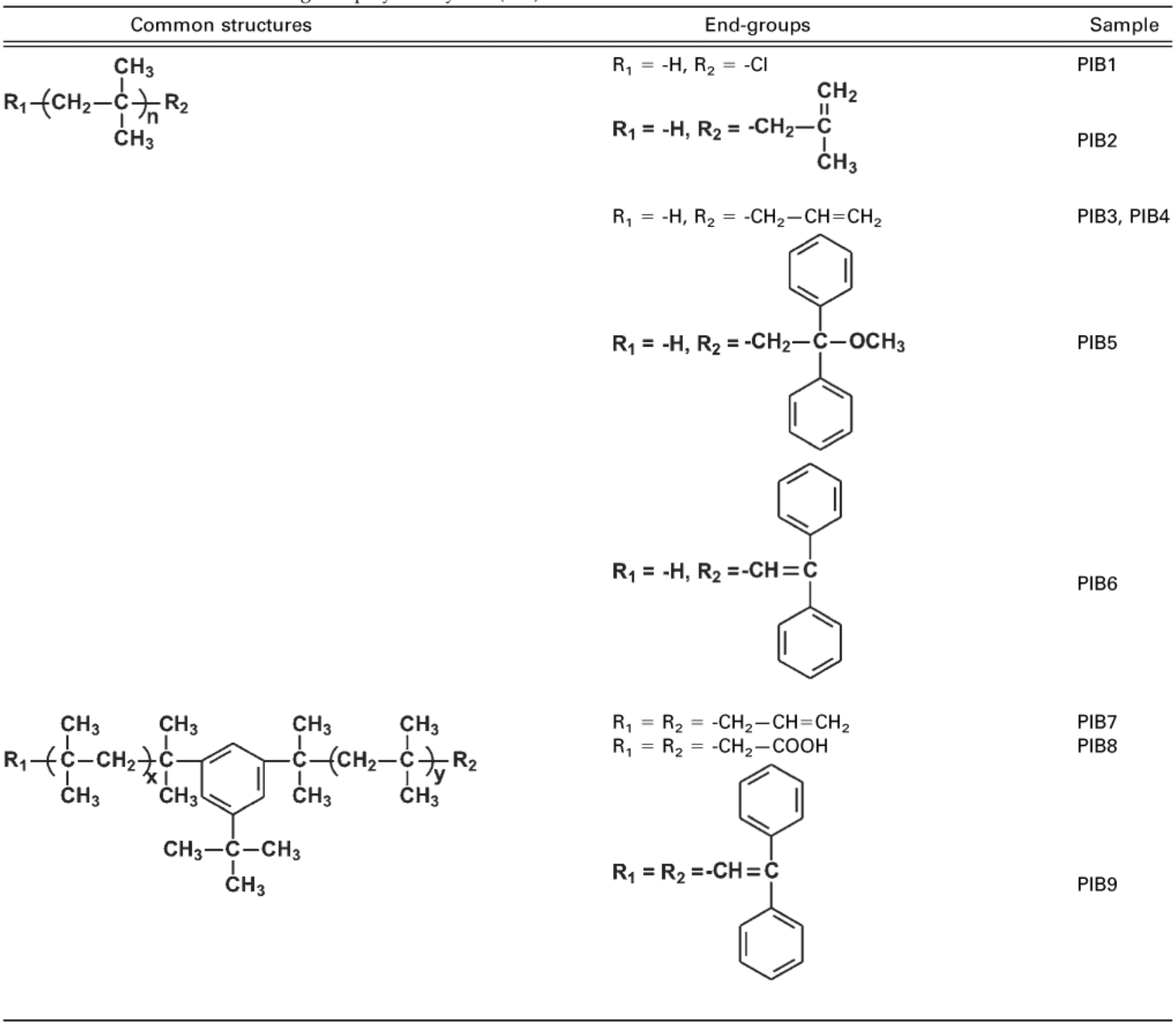

a 10:5:1 (vol/vol/v) ratio (matrix/polymer/cationization agent). A volume of $0.5 \mu \mathrm{L}$ of the solution was deposited onto a metal sample plate and allowed to air-dry.

Size exclusion chromatography (SEC). The molecular weights (MW) and the molecular weight distributions (MWD) of the PIB samples were determined by SEC analyses. A Waters 515 HPLC pump and a mixed-C column series with $10^{3}-10^{2}-10^{1}-5 \mathrm{~nm}$ pore sizes supplied by Polymer Laboratories were used. The detector was a dual Viscotek (Houston, TX, USA) differential refractometer/ viscometer, operating at room-temperature. THF was the mobile phase with a flow rate of $1.0 \mathrm{~mL} \mathrm{~min}^{-1}$. The collection and the analysis of the data were carried out with a Viscotek Trisec software, using the universal calibration method. The calibration curve was based on 18 narrow MWD linear polystyrene standards.

\section{Results and Discussion}

APPI-MS in the Negative Ion Mode (APPI(-)-MS)

The APPI(-)-MS spectra of all of the polyisobutylene (PIB) samples investigated show the presence of PIB chains ionized with chloride ions, i.e., $[\mathrm{M}+\mathrm{Cl}]^{-}$adduct ions were formed. The end groups of the PIBs and chloride ion attachment to the PIB chains were further supported by accurate mass measurements and by comparing the corresponding experimental and theoretical isotopic distributions calculated using the elemental compositions for some oligomers. As a representative example, Figure 1 shows the APPI(-)-MS spectrum of PIB8.

The APPI(-)-MS spectrum of PIB8 reveals two series of peaks. Series A ions correspond to the chlorinated adducts of PIB8 with two carboxyl termini. As seen in Figure 1, the series A ions appeared up to $m / z \sim 3000$, 


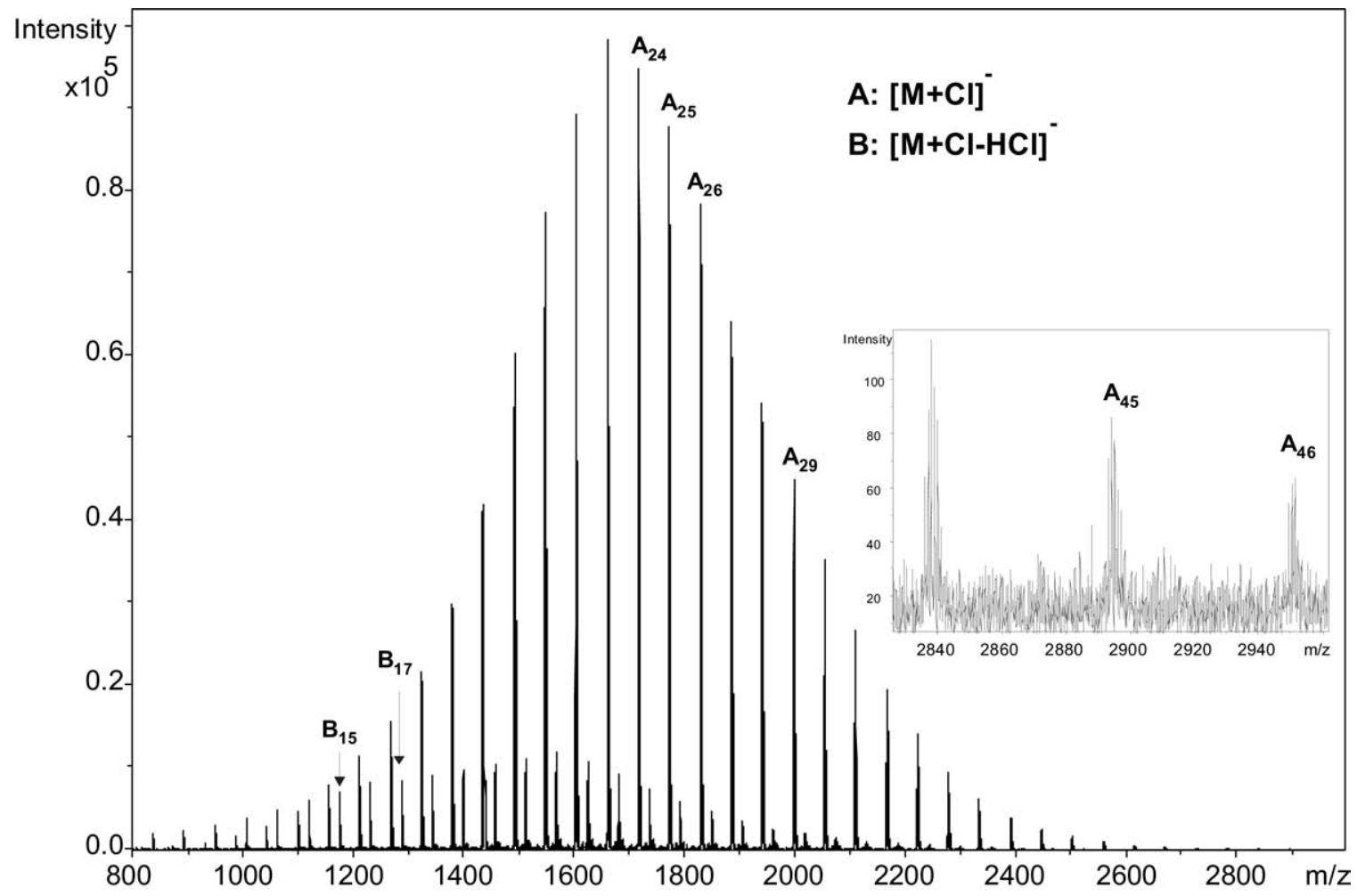

Figure 1. Negative ion atmospheric pressure photoionization mass spectrum of the sample PIB8. The numbers in the subscripts represent the numbers of the polyisobutylene units. The inset reveals the partial mass spectrum in the $m / z$ range of $2820-2980$.

which comprises about 47 isobutylene units. The additional low intensity series B ions are consistent with the negatively charged, deprotonated PIB8 molecules. The origin of the latter series will be discussed later. As another example for the applicability of APPI(-)-MS for the determination of the end groups of the PIB derivatives, the APPI(-)-MS spectrum of PIB1 is shown in the Supplemental Information, which can be found in the electronic version of this article.

The end groups of PIBs determined by APPI(-)-MS were entirely consistent with those given in Table 1 . Observations of the formation of chlorinated adduct ions for these PIB derivatives when using a chlorinated solvent $\left(\mathrm{CCl}_{4}\right)$ and a dopant (toluene) are in good accordance with our earlier studies obtained with other polyisobutylene derivatives and polyethylene waxes $[29,30]$.

To study the effects of the molecular weight of the PIB samples on the APPI(-)-MS spectra, the $\mathrm{M}_{n}$ values determined from the corresponding APPI(-)-MS spectra were compared to those obtained by size exclusion chromatography (SEC) and when it was possible, to those calculated from the MALDI-TOF MS spectra. The $\mathrm{M}_{n}, \mathrm{M}_{\mathrm{w}}$, and polydispersity (PD) data were calculated from the APPI(-)-MS and MALDI-TOF MS spectra according to eqs $1-3$,

$$
\mathrm{M}_{\mathrm{n}}=\frac{\sum \mathrm{I}_{\mathrm{i}} \mathrm{M}_{\mathrm{i}}}{\sum \mathrm{I}_{\mathrm{i}}}
$$

$$
\begin{aligned}
& \mathrm{M}_{\mathrm{w}}=\frac{\sum \mathrm{I}_{\mathrm{i}} \mathrm{M}_{\mathrm{i}}^{2}}{\sum \mathrm{I}_{\mathrm{i}} \mathrm{M}_{\mathrm{i}}} \\
& \mathrm{PD}=\mathrm{M}_{\mathrm{w}} / \mathrm{M}_{\mathrm{n}}
\end{aligned}
$$

where $I_{i}$ is the MS intensity of the $i^{\text {th }}$ oligomer with a mass of $M_{i}$ appearing in the mass spectrum. $M_{w}$ and PD are the weight-average molecular weight and the polydispersity, respectively (the mass of the cation, i.e., silver ion, or anion, i.e., chloride ion was subtracted before calculation). The $\mathrm{M}_{n}$ values determined by SEC, APPI(-)-MS and MALDI-TOF MS are summarized in Table 2.

As the data in Table 2 show, cationization of the PIB1 and PIB4 samples with silver ions failed under MALDI

Table 2. The $\mathrm{M}_{n} \mathrm{~s}$ determined by SEC, APPI(-)-MS and MALDI-TOF MS. The polydispersity values (PD) are shown in the brackets

\begin{tabular}{crrc}
\hline PIB samples & $\mathrm{M}_{n}$ (SEC) & $\mathrm{M}_{n}$ (APPI-) & $\mathrm{M}_{n}$ (MALDI) \\
\hline \hline PIB1 & $810(1.11)$ & $950(1.029)$ & - \\
PIB2 & $900(1.11)$ & $1010(1.014)$ & $720(1.022)$ \\
PIB3 & $900(1.09)$ & $1030(1.019)$ & $770(1.032)$ \\
PIB4 & $4500(1.25)$ & $1560(1.021)$ & - \\
PIB5 & $1160(1.08)$ & $1370(1.010)$ & $1270(1.024)$ \\
PIB6 & $2220(1.14)$ & $1620(1.010)$ & $1980(1.012)$ \\
PIB7 & $2120(1.15)$ & $1710(1.018)$ & $1940(1.012)$ \\
PIB8 & $1900(1.15)$ & $1670(1.025)$ & $2050(1.032)$ \\
PIB9 & $2410(1.10)$ & $1720(1.010)$ & $2170(1.012)$ \\
\hline
\end{tabular}


conditions. For the samples PIB2 and PIB3, although the resulting MS spectra were patterned by the presences of silver and matrix clusters in the low mass range, it was still possible to deduce $\mathrm{M}_{n}, \mathrm{M}_{\mathrm{w}}$ and PD values according to eqs $1-3$. It can be also inferred from the data in Table 2 that the $\mathrm{M}_{n}$ values determined by means of the three methods agree within the mass of a few isobutylene units for the PIB samples with $\mathrm{M}_{n}$ below $2000 \mathrm{Da}$. However, the deviations between the $\mathrm{M}_{n}$ values determined by SEC, APPI(-)-MS, and MALDI-TOF MS methods become more pronounced above $2000 \mathrm{Da}$. For example, the three methods give similar results for the $\mathrm{M}_{n}$ values of PIB3, however PIB4, which contains the same end group but has higher molecular weight than PIB3, APPI(-)-MS provides a considerably lower $\mathrm{M}_{n}$ value than SEC. On the other hand, MALDI-TOF MS failed to generate a mass spectrum for PIB4 most probably due to poor ionization efficiency. It seems reasonable that the relatively low $\mathrm{M}_{n}$ value by APPI(-)-MS may be a result of thermal degradation (fragmentation) of the longer chains and/or ineffective vaporization/gas-phase transfer processes for the higher molecular weight fraction. To gain deeper insight into the possible reasons for the occurrence of the "mass discrimination" effect observed in APPI(-)-MS for the higher molecular weight PIB samples, the mass spectra for the samples PIB3 and PIB4 were recorded at various vaporizer temperatures while keeping all of the other instrumental parameters constant. It is important to note that the samples PIB3 and PIB4 differ only in their $\mathrm{M}_{n}$ values, thereby the potential effect of the end group on the APPI(-)-MS spectra can be entirely excluded. In Figure 2, the variation of the most probable

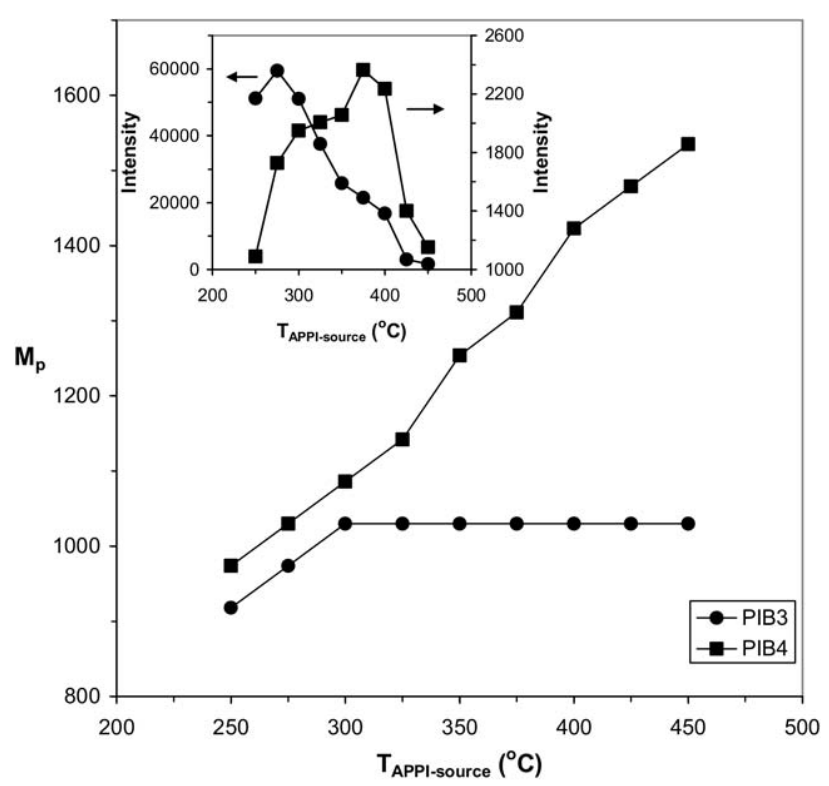

Figure 2. The variation of the most probable mass $\left(\mathrm{M}_{\mathrm{p}}\right)$ (the mass of the peak having the highest intensity) with the vaporizer temperature for the samples PIB3 (filled circle) and PIB4 (filled square). The inset shows the highest $\mathrm{M}_{\mathrm{p}}$ intensity versus vaporizer temperature curves for these samples. mass $\left(M_{p}\right)$, i.e., the mass of the peak having the highest intensity versus vaporizer temperature, is plotted for the samples PIB3 and PIB4 together with the inset showing the highest intensity versus vaporizer temperature curves for these samples.

Figure 2 shows that the $\mathrm{M}_{\mathrm{p}}$ for PIB3 increases from a vaporizer temperature of 250 to $300{ }^{\circ} \mathrm{C}$, but that it levels off at higher temperatures. The intensity of the $\mathrm{M}_{\mathrm{p}}$ peak reaches a maximum at $275{ }^{\circ} \mathrm{C}$ and then decreases gradually. However, in the case of PIB4, the value of $\mathrm{M}_{\mathrm{p}}$ continuously increases with the increasing vaporizer temperature; meanwhile its intensity reveals a maximum at around $375{ }^{\circ} \mathrm{C}$. The decrease of the intensities of the $M_{p}$ peaks with increasing vaporizer temperatures may be attributed to the decrease of the ionization efficiencies associated with the lower stability of the chlorinated adducts at these high temperatures. Furthermore, these investigations indicate that the $M_{p}$ for PIB3 may be accurate since it is no longer affected by the vaporizer temperature above $275^{\circ} \mathrm{C}$ while the $\mathrm{M}_{n}$ for PIB4 gradually increases with temperature. This is because more and more, longer chains will be amenable to mass analysis at higher vaporizer temperatures, thus shifting the $M_{p}$ to a higher value. Therefore, it is assumed that the increase of $M_{p}$ with increasing vaporizer temperatures for the PIB samples whose real $\mathrm{M}_{n}$ values are higher than ca. $2000 \mathrm{Da}$ may be due to a continuous increase in the efficiencies of the vaporization/ gas-phase transfer processes.

\section{Tandem Mass Spectrometric Study of PIB with Carboxyl Termini in the Negative Ion Mode of APPI-MS}

As the results have shown, all of the PIB samples investigated in this study showed the prevalent formation of adducts with chloride ions in the negative ion mode of APPI. However, when these adducts were subjected to collision-induced dissociation, considerable losses in the precursor signals were observed without formation of any product ions. These observations are consistent with our previous studies obtained for other polyisobutylene derivatives [29]. An increase of the collision energy resulted in the dissociation of the adducts into a neutral fragment and a chloride ion. The only exception was the PIB sample with carboxyl termini (PIB8). As it was discussed in the previous section, the APPI(-)-MS spectrum of PIB8 shows the predominant formation of adducts with chloride ions and an additional low intensity series of ions corresponding to the deprotonated PIB8 (Figure 1). These two series of ions may be formed in the APPI-source as a result of the competition between the chloride attachment and deprotonation processes. Interestingly, when we intended to select a particular deprotonated ion by the first quadruple, no corresponding signals were obtained. This observation clearly indicates that the deprotonated molecules are formed predominantly in the collision 
cell and not in the source. In the single MS-mode of operation, the collision energy is normally set to $5-8 \mathrm{eV}$ to provide enough kinetic energy for the ions to be transferred towards the TOF analyzer. However, even such a relatively low collision energy induces fragmentation of the chlorinated adduct ions to a low extent to give deprotonated ions by the loss of an $\mathrm{HCl}$ molecule. Indeed, by increasing the collision energy in the single MS-mode, while keeping all of the other instrumental parameters constant, a significant increase in the intensity ratio of the deprotonated/chlorinated adduct ion was attained. For example, the intensity ratio of deprotonated molecules belonging to the chlorinated adduct ion for the sample PIB8 with 20 repeat units increased from 0.17 to 1.5 when the collision energy was elevated from 5 to $15 \mathrm{eV}$. It was also found that lighter PIB8 chains tended to release $\mathrm{HCl}$ more readily than the heavier ones. For instance, the intensity ratio of the deprotonated/chlorinated adduct ion at a collision energy of $11 \mathrm{eV}$ is 0.16 and 1.9 for PIB8 with 28 and 15 repeat units, respectively. This is consistent with the theory of gas-phase unimolecular decomposition; the higher the molecular weight, i.e., the higher the number of degrees of freedom, the lower the energy imparted to breaking bonds. Consequently, the lighter chains tended to fragment with higher rates than the heavier ones, i.e., producing higher deprotonated than chlorinated adduct-ion ratios within the time frame of the mass spectrometric experiments. In addition, the total amount of energy transferred from the collision gas to the analyte ion in a single collision also decreases with the increasing mass of the analyte.

In further studies, the chlorinated adduct of PIB8 was selected and then subjected to collision-induced dissociation to gain structural information. The firstgeneration product ion spectrum (MS/MS) of the chlorinated PIB8 $\left(\left[\mathrm{M}+\mathrm{Cl}^{-}\right)\right.$is shown in Figure 3.

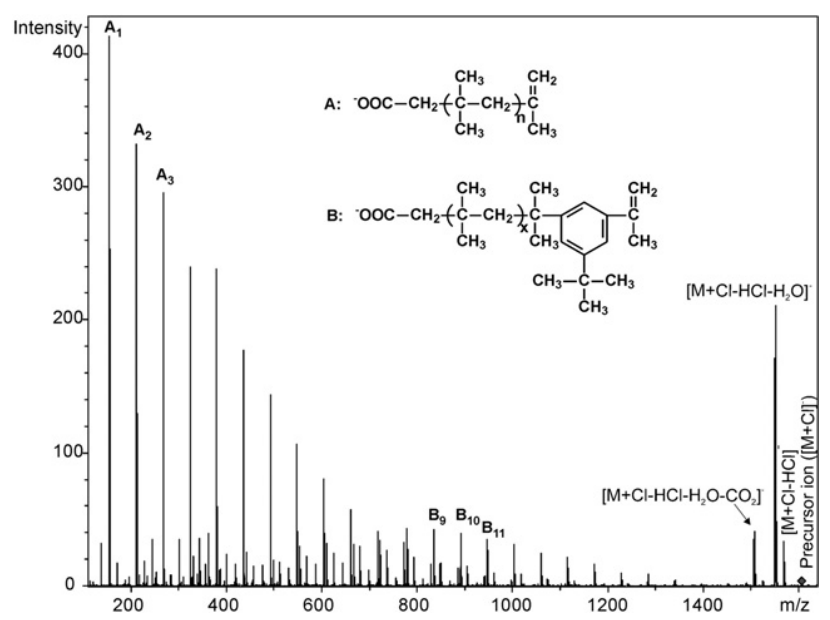

Figure 3. First-generation product ion spectrum (MS/MS) of the chlorinated PIB8 with isobutylene units $n=22$ ( $m / z$ 1603). The numbers in the subscripts represent the numbers of the polyisobutylene units $(n)$. The collision energy was $130 \mathrm{eV}$ in the laboratory frame.
Figure 3 shows that the precursor ion loses $\mathrm{HCl}$, $\mathrm{H}_{2} \mathrm{O}$, and $\mathrm{CO}_{2}$ molecules to yield $[\mathrm{M}+\mathrm{Cl}-\mathrm{HCl}]^{-}$ (deprotonated molecule), $\left[\mathrm{M}+\mathrm{Cl}-\mathrm{HCl}-\mathrm{H}_{2} \mathrm{O}\right]^{-}$, and $\left[\mathrm{M}+\mathrm{Cl}-\mathrm{HCl}-\mathrm{H}_{2} \mathrm{O}-\mathrm{CO}_{2}\right]^{-}$product ions that are presumably formed in consecutive and parallel processes. Moreover, what is structurally more important is the appearance of PIB-series, i.e., series A and series B that are produced by cleavages of the PIB chain. Series A ions are separated from each other by a distance corresponding to a single isobutylene unit and have acetate and 2-propenyl chain-ends as indicated in Figure 3 inset (in good agreement with the expected structure for PIB8). Note that series A ions do not contain the aromatic initiator moiety and their intensities decrease monotonically in the $m / z$ range $155-999$, corresponding to a number of repeat units between 3 and 12. Similar to series $A$, series $B$ ions are produced by $C-C$ cleavage yielding product ions with acetate chain-ends and with termini containing the initiator moiety. Unlike series A, series B also contains the initiator moiety. The product ions of series B reveal an intensity distribution centered at $m / z 777$. It is worth considering whether the resulted MS/MS intensity distribution for series $B$ reflects the arm distribution in the original chains. It can be expected theoretically that the repeat units and the bifunctional initiator moiety are distributed statistically within the chain. Therefore, owing to the statistical nature of the polymerization reaction, each oligomer with a particular number of repeat units is a mixture of chains consisting of PIB-arms of different lengths. In our case, i.e., for an oligomer with $\mathrm{x}+\mathrm{y}=n=22$, it means that one can find chains with arms spanning from $x=0$ to 22 isobutylene units. This means that $x=$ 0 and $x=22$ represent the cases when only one of the two ends of the bifunctional initiator is propagated, while $x=11$ corresponds to an oligomer having two identical arm-lengths. To describe the arm-length distribution, the Bernoulli distribution is proposed,

$$
\mathrm{Y}(\mathrm{n}, \mathrm{k})=\frac{\mathrm{n} !}{\mathrm{k} !(\mathrm{n}-\mathrm{k}) !} \mathrm{p}^{\mathrm{n}} \mathrm{q}^{\mathrm{n}-\mathrm{k}}
$$

where $Y(n, k)$ is the probability of finding an oligomer with an arm composed of a number of repeat units $\mathrm{k}, n$ is the total number of repeat units, $\mathrm{p}$ and $\mathrm{q}$ are the probabilities of addition of a monomer unit to the one or the other end of the growing chain.

The reactivities of the two functions of the symmetrical bifunctional initiator used for polymerization are expected to be identical. Furthermore, supposing that the growing chain-ends react with the monomer independently of the arm length, it is reasonable to assume that $p=q=1 / 2$. Setting these values into eq 4 , the theoretical arm-length distribution can be calculated and compared with the experimental MS/MS intensity distribution. The experimental MS/MS intensity distribution for PIB8 $(m / z$ 1603, $n=22)$ together with the arm-length distribution calculated by eq 4 for that oligomer are plotted in Figure 4. 


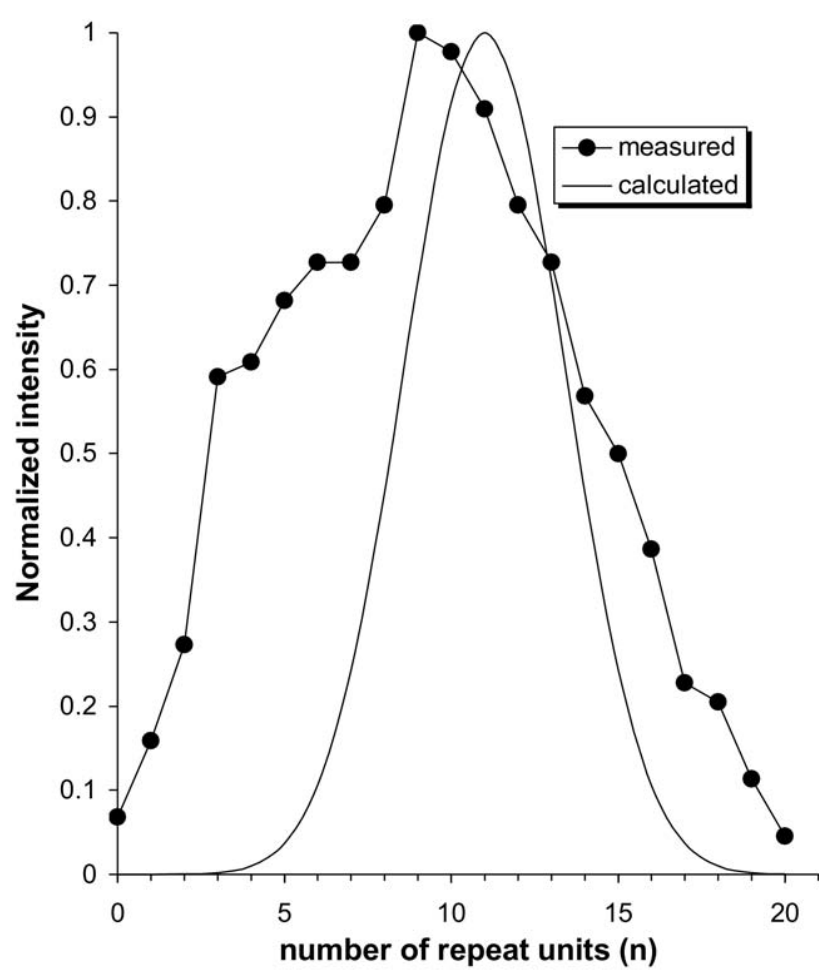

Figure 4. The normalized experimental MS/MS intensity distribution and the calculated arm-length distribution for PIB8 $(\mathrm{m} / \mathrm{z}$ $1603, n=22$ ). The arm-length distribution was calculated by Eq. 4 .

As seen in Figure 4, the maximum of the experimental curve appears at approximately the same number of repeat units as that of the calculated one, namely at $n=$ 10-11. In addition, the trend of the experimental curve is similar to the theoretical one. Such a good agreement between the theory and experiment suggests that a closely symmetrical PIB8 with certain heterogeneity in the arms was formed, and the bond cleavages yielding series B predominantly occurred at the initiator moiety, as depicted in Figure 4. The deviations obtained between the experimental and the calculated curves may arise if the reactivity of the growing chain towards the monomer (isobutylene) depends on the arm length, and fragmentations leading to the formation of the B-series may occur to some extent along the whole arm. Fragmentation preferentially occurring at the initiator junction can be rationalized by taking into account that these bond-breaking reactions generate a series of product ions with unsaturated bonds conjugated with the aromatic ring, which ensures a relatively high stability for these product ions.

Series A ions may be formed by parallel fragmentations along whole arms; therefore, these ions carry less structural information compared with the series B ions. Moreover, it is important to note that although the analytical importance of series $A$ is far below that of series B, it allows for an observation of the armheterogeneity in a bifunctional system. For instance, series A ion signals can be observed up to $m / z 1000$, i.e., corresponding to $x=13$, which means that oligomers with 22 repeat units must contain PIB8 molecules, and one of its two arms is composed of at least 13 repeat units. Considering the fragmentation mechanism leading to the formation of series $\mathrm{A}$ and series $\mathrm{B}$, whose negative charges are definitely located at the ends of the fragmented chains, likely both series were formed by charge remote fragmentations (CRFs) [36]. Although CRFs are not commonly observed under low-energy collision-induced dissociation (CID), they have been observed for cases when the charge is localized, e.g., for fatty acids [37, 38] and polyethylene glycol derivatives cationized with bivalent metal ions [39].

\section{APPI-MS in the Positive Ion Mode (APPI(+)-MS)}

In the positive ion mode, almost all of the samples investigated showed considerable fragmentation. This observation is consistent with our previous results obtained with other polyisobutylene derivatives [29]. Although intact polymer ions can hardly be achieved in positive mode, the APPI(+)-MS spectra may offer information on the chain and the end-group structure, therefore it is worth considering them in more detail.

In the APPI(+)-MS spectra of the samples PIB1, PIB2, PIB3, and PIB4, the intensity distributions are skewed to lower masses and none of the peaks correspond to the polyisobutylene derivative with the expected end groups. The observations indicate fragmentation of the original PIB chains in the ion source. The APPI(+)-MS spectrum of PIB2 together with the proposed structure of the fragmented chains are shown in the Supplemental Information. A series of $\mathrm{H}\left(\mathrm{C}_{4} \mathrm{H}_{8}\right)_{n} \mathrm{CH}_{2}{ }^{+}$ions were formed in the case of PIB2. Formation of $\mathrm{H}\left(\mathrm{C}_{4} \mathrm{H}_{8}\right)_{n} \mathrm{CH}_{2}{ }^{+}$ ions was also observed in the $\mathrm{APPI}(+)$-MS spectrum of PIB1. Moreover, in the case of PIB3 and PIB4, $\mathrm{H}\left(\mathrm{C}_{4} \mathrm{H}_{8}\right)_{n}{ }^{+}$ions were formed. It seems reasonable that for the samples PIB1-PIB4, protonation of the end groups may take place such that the protonated molecules release a $C_{3}$ neutral unit (propene). This release may cause formation of $\mathrm{H}\left(\mathrm{C}_{4} \mathrm{H}_{8}\right)_{n} \mathrm{CH}_{2}{ }^{+}$ions in the case of PIB2 (isobutenyl chain-end) and generation of $\mathrm{H}\left(\mathrm{C}_{4} \mathrm{H}_{8}\right)_{n}{ }^{+}$ions in the case of PIB3 and PIB4 (allylic chain-end). For PIB1, elimination of an $\mathrm{HCl}$ molecule might occur before loss of the neutral $C_{3}$ unit. On the other hand, the positive charge can also migrate from the chain-end towards the interior of the chain to yield a series of fragment ions differing by isobutylene units.

For sample PIB5, the APPI(+)-MS spectrum reveals the dominant presence of two series with end groups that do not correspond to the expected ones. The most intense series can be derived from the expected structure by loss of a benzene molecule and the second, less intense series differs by $28 \mathrm{Da}$ in mass from the latter one. Therefore, it is reasonable to assume that the original end group may undergo protonation and subsequent fast decomposition by the loss of a benzene molecule, and may further release $\mathrm{CO}$, leading to the appearance of a second series of peaks. However, this second series of peaks may be formed directly from the 
original structure by the loss of a benzaldehyde molecule, and, to support this conclusion, an MS/MS experiment was performed. The peak at $m / z 1144$ from the first series (formed by the loss of a benzene molecule) was selected for CID and the resulting MS/MS spectrum showed no loss of a $\mathrm{CO}$ molecule from the precursor ion. Therefore, likely losses of benzene and benzaldehyde take place in parallel ways.

In the APPI(+)-MS spectrum of the sample PIB6, no considerable fragmentation was observed. The intensity distribution is rather similar to that obtained in negative mode with the chloride ion attachment technique, but the absolute intensity was lower by about one order of magnitude. Interestingly, it was found that radical molecular ions were formed in this case, i.e., an electron withdrawal most likely from the end group (diphenylethylene) takes place to give molecular ions with odd numbers of electrons. This unusual observation can be rationalized considering that electron withdrawal from the double bonds can easily be achieved, and the formed positive charges are stabilized and localized by the two phenyl rings, thereby preventing chargemigrations and further fragmentations.

The most intriguing observations were obtained with the samples PIB7, PIB8, and PIB9. All of these samples contained an aromatic initiator moiety but with different end groups. In the APPI(+)-MS spectra of PIB8 and PIB9, two distinct series of peaks appeared, as shown for PIB9 in Figure 5.

The assignment of series A in the APPI(+)-MS spectra of the three samples investigated was not straightforward. Based on the isotopic patterns of the series A ions, we concluded that each must contain one chlorine atom, and that certain additions of a unit with a mass of 28 and a chlorine atom (or other combinations) gave the corresponding $\mathrm{m} / \mathrm{z}$ values. Using the accurate masses, the best result was obtained when addition of $\mathrm{COCl}^{+}$to the oligomers was taken into account, albeit the agreement between the measured and calculated masses for the corresponding adducts were not quite good (the differences between the measured and calculated masses were 0.02 on the average). The origin of the $\mathrm{COCl}^{+}$species may be due to the reaction of $\mathrm{CCl}_{4}$ with $\mathrm{O}_{2}$ and $\mathrm{H}_{2} \mathrm{O}$, which inherently occurs in the ion source upon irradiation by UV photons. It has been shown [40] that the presence of $\mathrm{O}_{2}$ cannot be completely excluded as the appearance of various ions has been associated with its presence in the ion source. Interestingly, although we failed to find out other species related to $\mathrm{COCl}^{+}$or $\mathrm{COCl}_{2}$ in positive ion mode, the formation of clusters of $\mathrm{COCl}_{2}$ as $\left(\mathrm{COCl}_{2}\right)_{x} \mathrm{Cl}^{-}$with $\mathrm{x}=2-4$ was observed in negative ion mode. Despite the uncertainties associated with the observed mass differences, the only rationale we could derive for the origin of series $\mathrm{A}$ is therefore the attachment of $\mathrm{COCl}^{+}$to the polymer chains. Since these "mysterious" series occurred significantly for the PIB samples having an aromatic moiety inside, independent of their end groups, it seems likely that the presence of such a series is linked predominantly to the presence of an aromatic initiator moiety. Hence, $\mathrm{COCl}^{+}$attaches presumably to the aromatic initiator moiety. However, the MS/MS spectra of some $[\mathrm{M}+\mathrm{COCl}]^{+}$ions showed no formation of any product ions, and a decrease in the precursor ion signal was found as the collision energy was increased. This information is important from two respects. (1) Dissociation of the adduct may take place to give a neutral fragment and a cation. Since the mass of $\mathrm{COCl}^{+}$is very close to the lower mass limit of our instrument (50-60 Da), it proves that the mass of the cation being released has to be lower than the lower mass limit, otherwise it should have been observed in the MS/MS spectrum. (2) Series

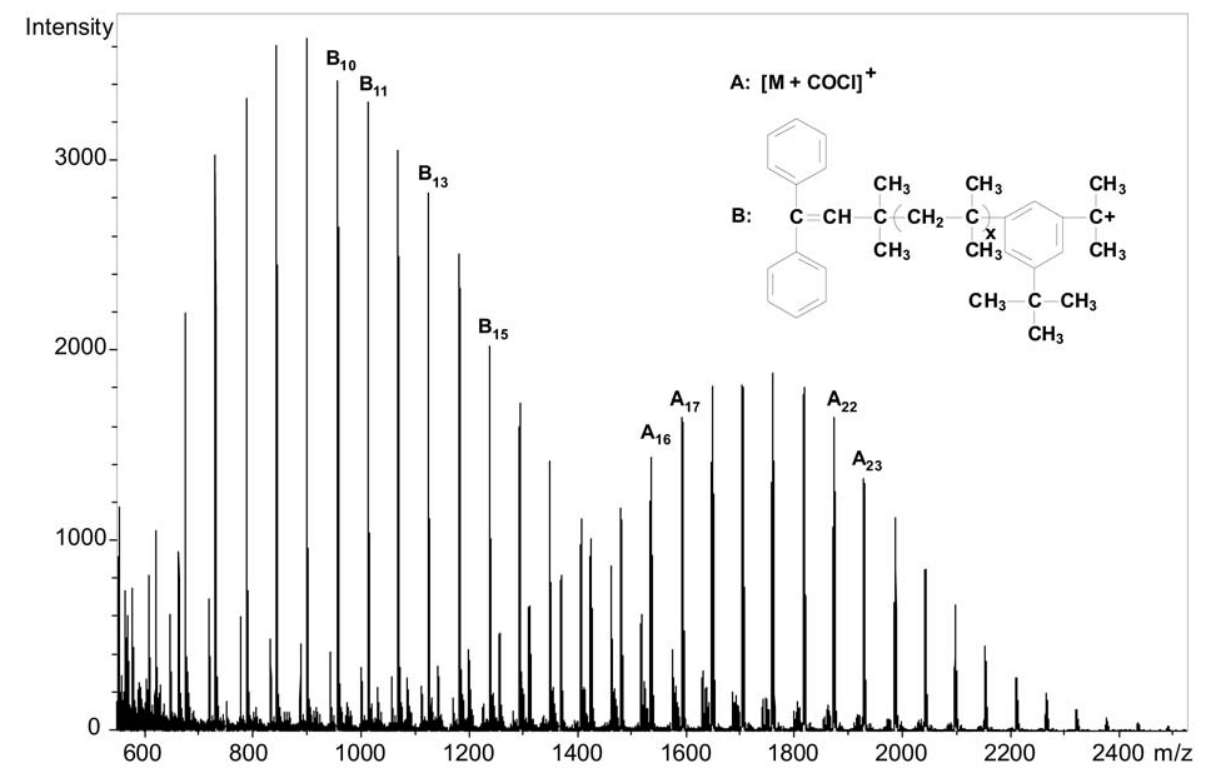

Figure 5. The APPI(+)-MS spectrum of PIB9. The numbers in the subscripts represent the numbers of the polyisobutylene units $(n)$. 
B cannot originate from series $A$, since fragmentation of the series A ions by MS/MS did not yield any series B ions. Thus, series B ions may be formed from their corresponding protonated oligomers by chain cleavage, which occurs most preferably at the initiator moiety to form the "half-armed" series B ions with the proposed structure as shown in Figure 5.

Providing that the fragmentations take place overwhelmingly at the initiator moiety, the resulting intensity distribution for the series B ions will reflect the "half-arm" distribution of series A. To calculate the expected APPI(+)-MS intensity distribution for the series $B$ ions, the intensity distribution of series $A$ and the binomial distribution (eq 4) for a two-arm initiator were combined to get eq 5 ,

$$
\mathrm{I}_{\mathrm{B}}(\mathrm{k})=\mathrm{C} \sum_{\mathrm{n}=\mathrm{n}_{\min }}^{\mathrm{n}_{\max }} \frac{\mathrm{n} !}{\mathrm{k} !(\mathrm{n}-\mathrm{k}) !} \mathrm{I}_{\mathrm{A}}(\mathrm{n})(1 / 2)^{\mathrm{n}} \quad \mathrm{n}_{\min } \geq \mathrm{k}
$$

where $\mathrm{I}_{\mathrm{A}}(n)$ is the $\mathrm{APPI}(+)$-MS intensity of a series A ion with a number of repeat units $n, I_{B}(k)$ being the calculated $\operatorname{APPI}(+)-\mathrm{MS}$ intensity of a series $\mathrm{B}$ ion with a number of repeat unit $k$, and $C$ is a scaling factor that allows the calculated intensity to be scaled up to the experimental ones. The parameters $n_{\min }$ and $n_{\max }$ are the observed lowest and highest number of the repeat units for series A.

The experimental intensity distributions for series A and series $B$ together with the intensity distribution calculated by eq 5 as a function of the number of the repeat units are shown in Figure 6.

As it can be seen in Figure 6, the maximum intensity of series $A$ is 20 repeat units, and that of series $B$

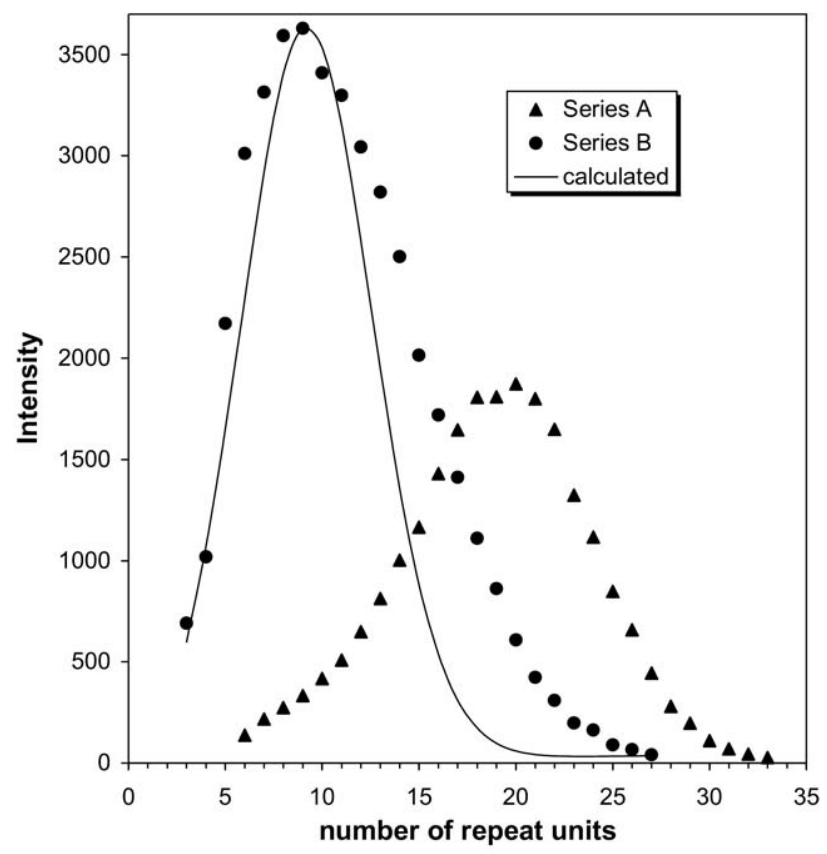

Figure 6. The experimental intensity distributions for series A and series $\mathrm{B}$. The solid line shows the intensity distribution for series A calculated by eq 5 . appears at 10 repeat units, indicating that chains with closely symmetrical arms were formed upon polymerization. The calculated intensity distribution for series A fits quite well to the experimental one. It should be noted that simply halving the number of the repeat units belonging to series A and calculating the intensity distribution for series $B$ in that way gives narrower distribution that deviates more from the experimental one than that calculated by eq 5 . Although there may be some uncertainties associated with the dependences of the ionization efficiency and the rate of polymerization on the chain length, the mass discriminations by MSsampling and the detection systems, the agreement between the theory and the experiment is quite good.

\section{Conclusions}

APPI(-)-MS has proven to be capable of determining the end groups of PIBs with varying molecular weights via the formation of adducts with chloride ions formed in situ from $\mathrm{CCl}_{4}$ in the presence of toluene dopant. However, large deviations in the $\mathrm{M}_{n}$ values determined by APPI(-)-MS and SEC can be expected for PIBs with molecular weights over 2000 Da. Therefore, it is advisable to use higher vaporizing temperatures for the PIB derivatives to obtain accurate $M_{n}$ values even if it sometimes comes at the expense of sensitivity. The MS/MS spectra obtained with the PIB carboxy derivatives containing a bifunctional aromatic initiator moiety can be used to estimate the "arm-length" distribution ensuring better insight into the mechanism of the polymerization reaction.

The resulting "half-armed" distribution appearing in the $\mathrm{APPI}(+)$-MS spectra of PIBs with a bifunctional aromatic moiety can also be used to render the "armlength" distribution in the original polymer molecules. Finally, as it was demonstrated, $\operatorname{APPI}(-)-\mathrm{MS}$ is capable of detecting highly nonpolar polymers with no significant dependence on their end groups. Therefore, it is reasonable to deduce that $\mathrm{APPI}(-)-\mathrm{MS}$ may be the best method when one has to analyze the mass of low molecular weight nonpolar polymers.

\section{Acknowledgments}

The authors acknowledge financial support for this work by grants K-62213, K-72524, and MU-00204/2001 from OTKA (National Scientific Research Fund, Hungary) and grant GVOP-3.2.1.2004-04-0152/3.0.

\section{Appendix A Supplementary Material}

Supplementary material associated with this article may be found in the online version at doi:10.1016/ j.jasms.2009.08.025. 


\section{References}

1. Varion, J.-P.; Spassky, N. Industrial Cationic Polymerizations: An Overview In Cationic Polymerizations: Mechanism, Synthesis, and Applications. Matyjaszewsky, K. Ed.; Marcel Dekker, Inc.: New York, Basel, Hong Kong, 1996, p. 683.

2. Iván, B.; Almdal, K.; Mortensen, K.; Johannsen, I.; Kops, J. Synthesis, Characterization, and Structural Investigations of Poly(Ethyl Acrylate)1-Polyisobutylene Bicomponent Co-Network. Macromolecules 2001, 34, 1579-1585.

3. Isayeva, S. I.; Yankovski, S. A.; Kennedy, J. P. Amphiphilic Networks. Part XVII. Novel Amphiphilic Membranes of Poly( $N, N$-Dimethyl Acrylamide) Crosslinked with Octamethacrylate Polyisobutylene Stars. Polym. Bull. 2002, 48, 475-482.

4. Kennedy, J. P.; Fenyvesi, G.; Levy, R. P.; Rosenthal, K. S. Amphiphilic Networks. XV. Amphiphilic Membranes with Controlled Mesh Dimensions for Insulin Delivery. Macromol. Symp. 2001, 172, 56-66.

5. Pergushov, D. V.; Remizova, E. V.; Gradzielski, M.; Lindner, P.; Feldthusen, J.; Zezin, A. B.; Müller, A. H. E.; Kabanov, V. A. Micelles of Polyisobutylene-block-Poly(Methacrylic Acid) Diblock Copolymers and Their Water-Soluble Interpolyelectrolyte Complexes Formed with Quaternized Poly(4-Vinylpyridine). Polymer 2004, 45, 367-378.

6. Burkhardt, M.; Ruppel, M.; Tea, S.; Drechsler, M.; Schweins, R.; Pergushov, D. V.; Gradzielski, M.; Zezin, A. B.; Müller, A. H. E. WaterSoluble Interpolyelectrolyte Complexes of Polyisobutylene-BlockPoly(Methacrylic Acid) Micelles: Formation and Properties. Langmuir 2008, 24, 1769-1777

7. Pergushov, D. V.; Remizova, E. V.; Gradzielski, M.; Lindner, P.; Feldthusen, J.; Zezin, A. B.; Müller, A. H. E.; Kabanov, V. A. Micelles of Polyisobutylene-Block-Poly(Methacrylic Acid) Diblock Copolymers and Their Water-Soluble Interpolyelectrolyte Complexes Formed with Quaternized Poly(4-Vinylpyridine). Polymer 2004, 45, 367-378.

8. Yun, J.; Faust, R.; Szilágyi, Sz. L.; Kéki, S.; Zsuga, M. Effect of Architecture on the Micellar Properties of Amphiphilic Block Copolymers: Comparison of $\mathrm{AB}$ Linear Diblock, $\mathrm{A}^{1} \mathrm{~A}^{2} \mathrm{~B}$, and $\mathrm{A} 2 \mathrm{~B}$ Heteroarm Star Block Copolymers. Macromolecules 2003, 36, 1717.

9. Karas, M.; Hillenkamp, F. Laser Desorption Ionization of Proteins with Molecular Masses Exceeding 10,000 Daltons. Anal. Chem. 1988, 60, 2299-2301.

10. Tanaka, K.; Waki, H.; Ido, Y.; Akita, S.; Yoshida, T. Protein and Polymer Analyse up to $m / z 100,000$ by Laser Ionization Time-of-Flight Mass Spectrometry. Rapid Commun. Mass Spectrom. 1988, 2, 151-153.

11. Wong, S. F.; Meng, C. K.; Fenn, J. B. Multiple Charging in Electrospray Ionization of Poly(Ethylene Glycols). J. Phys. Chem. 1988, 92, 546-550.

12. Kéki, S.; Deák, G.; Mayer-Posner, F. J.; Zsuga, M. MALDI-TOF MS Characterization of Dihydroxy Telechelic Polyisobutylene. Macromol. Rapid Commun. 2000, 21,770-774.

13. Kéki, S.; Nagy, M.; Deák, G.; Lévai, A.; Zsuga, M. Dimethyldioxirane as a New and Effective Oxidation Agent for the Epoxidation of $\alpha, \omega$ di(Isobutenyl)Polyisobutylene: A Convenient Synthesis of $\alpha, \omega$-di(2Methyl-3-Hydroxypropyl)Polyisobutylene. J. Polym. Sci. Part A Polym. Chem. 2002, 40, 3974-3986.

14. Kéki, S.; Nagy, M.; Deák, G.; Zsuga, M.; Herczegh, P. Matrix-Assisted Laser Desorption/Ionization Mass Spectrometric Study of Bis(Imidazole1-Carboxylate) Endfunctionalized Polymers. J. Am. Soc. Mass Spectrom. 2003, 14, 117-123.

15. Nagy, M.; Kéki, S.; Orosz, L.; Deák, G.; Herczegh, P.; Lévai, A.; Zsuga, M. Novel and Simple Synthesis of Carboxyl-Terminated Polyisobutylenes. Macromolecules 2005, 38, 4043-4046.

16. Ji, H. N.; Sato, N.; Nakamura, Y.; Wan, Y. N.; Howell, A.; Thomas, Q. A.; Storey, R. F.; Nonidez, W. K.; Mays, J. W. Characterization of Polyisobutylene by Matrix-Assisted Laser Desorption Ionization Time-of-Flight Mass Spectrometry. Macromolecules 2002, 35, 1196-1199.

17. Harrison, J. J.; Mijares, C. M.; Cheng, M. T.; Hudson, J. Negative Ion Electrospray Ionization Mass Spectrum of Polyisobutenylsuccinic Anhydride: Implications for Isobutylene Polymerization Mechanism. Macromolecules 2002, 35, 2494-2500.

18. Robb, D.; Covey, T.; Bruins, A. Atmospheric Pressure Photoionization: An Ionization Method for Liquid Chromatography-Mass Spectrometry. Anal. Chem. 2000, 72, 3653-3659.

19. Syage, J. A.; Evans, M. D.; Hanold, K. A. Photoionization Mass Spectrometry. Am. Lab. 2000, 32, 24-29.

20. Kauppila, T. J.; Kuuranne, T.; Meurer, E. C.; Eberlin, M. N.; Kotiaho, T.; Kostiainen, R. Atmospheric Pressure Photoionization Mass Spectrome- try. Ionization Mechanism and the Effect of Solvent on the Ionization of Naphthalenes. Anal. Chem. 2002, 74, 5470-5479.

21. Short, L. C.; Cai, S.-S.; Syage, J. A. APPI-MS: Effects of Mobile Phases and VUV Lamps on the Detection of PAH Compounds. J Am. Soc. Mass Spectrom. 2007, 18, 589-599.

22. Moriwaki, H.; Ishitake, M.; Yoshikawa, S.; Miyakoda, H.; Alary, J. F. Determination of Polycyclic Aromatic Hydrocarbons in Sediment by Liquid Chromatography-Atmospheric Pressure Photoionization-Mass Spectrometry. Anal. Sci. 2004, 20, 375-377.

23. Cai, S. S.; Syage, J. A. Comparison of Atmospheric Pressure Photoionization, Atmospheric Pressure Chemical Ionization, and Electrospray Ionization Mass Spectrometry for Analysis of Lipids. Anal. Chem. 2006, 78, 1191-1199.

24. Cai, S. S.; Syage, J. A. Atmospheric Pressure Photoionization Mass Spectrometry for Analysis of Fatty Acid and Acylglycerol Lipids. J. Chromatogr. A 2006, 1110, 15-26.

25. Delobel, A.; Roy, S.; Touboul, D.; Gaudin, K.; Germain, D. P.; Baillet, A.; Brion, F.; Prognon, P.; Chaminade, P.; Laprevote, O. Atmospheric Pressure Photoionization Coupled to Porous Graphitic Carbon Liquid Chromatography for the Analysis of Globotriaosylceramides. Application to Fabry Disease. J. Mass Spectrom. 2006, 41, 50-58.

26. Greig, M. J.; Bolanos, B.; Quenzer, T.; Bylund, J. M. R. Cyclotron Resonance Mass Spectrometry Using Atmospheric Pressure Photoionization for High-Resolution Analyses of Corticosteroids. Rapid Commun. Mass Spectrom. 2003, 17(24), 2763-2768.

27. Kauppila, T. J.; Nikkola, T.; Ketola, R. A.; Kostiainen, R. Atmospheric Pressure Photoionization-Mass Spectrometry and Atmospheric Pressure Chemical Ionization-Mass Spectrometry of Neurotransmitters. J. Mass Spectrom. 2006, 41, 781-789.

28. Trosken, E. R.; Straube, E.; Lutz, W. K.; Volkel, W.; Patten, C. Quantitation of Lanosterol and its Major Metabolite FF-MAS in an Inhibition Assay of CYP51 by Azoles with Atmospheric Pressure Photoionization Based LC-MS/MS. J. Am. Soc. Mass Spectrom. 2004, 15, 1216-1221.

29. Kéki, S.; Török, J.; Nagy, L.; Zsuga, M. Atmospheric Pressure Photoionization Mass Spectrometry of Polyisobutylene Derivatives. J. Am. Soc. Mass Spectrom. 2008, 19, 656-665.

30. Kéki, S.; Nagy, L.; Kuki, Á.; Zsuga, M. A New Method for Mass Spectrometry of Polyethylene Waxes: The Chloride Ion Attachment Technique by Atmospheric Pressure Photoionization. Macromolecules 2008, 41, 3772 .

31. Kennedy, J.P.; Chang, V. S. C.; Smith, R. A.; Iván, B. New Telechelic Polymers and Sequential Copolymers by Polyfunctional Initiator-Transfer Agents (Inifers) V. Synthesis of $\alpha$-tert-Butyl- $\omega$-Isopropenylpolyisobutylene and $\alpha, \omega$-di(Isopropenyl)Polyisobutylene. Polym. Bull. 1979, 1, 575-580.

32. Iván, B.; Kennedy, J. P. Living Carbocationic Polymerization 30 One-Pot Synthesis of Allyl-Terminated Linear and Tri-Arm Star Polyisobutylenes, and Epoxy-Telechelic and Hydroxy-Telechelic Therefrom. I. Polym. Sci. Part A Chem. Ed. 1990, 28, 89-104.

33. Feldthusen, J.; Iván, B.; Müller, A. H. E.; Kops, J. Synthesis of Linear and Three-Arm Star tert-Chlorine-Telechelic Polyisobutylenes by a TwoStep Conventional Laboratory Process. Macromol. Rapid Commun. 1997, $18,417-425$.

34. Feldthusen, J.; Iván, B.; Müller, A. H. E.; Kops, J. Endfunctional Polymers by Functionalization of Living Cationic Chain-Ends with 1,1-Diphenylethylene. Macromol. Reports 1995, A32, 639-647.

35. Lange, A.; Mach, H.; Rath, H.-P.; Karl, U.; Iván, B.; Groh, P. W.; Nagy, Zs. T.; Pálfi, V. US Patent 2006, 0276588 A1.

36. Cheng, C.; Gross, M. L. Charge Remote Fragmentation: An Account of Research on Mechanisms and Applications. Mass Spectrom. Rev. 2000, $19,398-420$.

37. Afonso, C.; Riu, A.; Xu, Y.; Fournier, F.; Tabet, J. C. Structural Characterization of Fatty Acids Cationized with Copper by Electrospray Ionization Mass Spectrometry Under Low-Energy Collision-Induced Dissociation. J. Mass Spectrom. 2005, 40, 342-349.

38. Wheelan, P.; Zirrolli, J. A.; Murphy, R. C. Electrospray Ionization and Low Energy Tandem Mass Spectrometry of Polyhydroxy Unsaturated Fatty Acids. J. Am. Soc. Mass Spectrom. 1996, 7, 140-149.

39. Chen, R.; Li, L. Lithium and Transition Metal Ions Enable Low Energy Collision-Induced Dissociation of Polyglycols in Electrospray Ionization Mass Spectrometry. J. Am. Soc. Mass Spectrom. 2001, 12, 832-839.

40. Kauppila, T. J.; Kotiaho, T.; Kostiainen, R.; Bruins, A. P. Negative Ion-Atmospheric Pressure Photoionization Mass Spectrometry. J. Am Soc. Mass Spectrom. 2004, 15, 203-211. 